\title{
PREVALENCE OF SUB-CLINICAL MASTITIS AT BANARIPARA UPAZILLA, BARISAL
}

\author{
D. Biswas* and T. Sarker \\ Department of Medicine, Surgery and Obstetrics, Faculty of Animal Science and Veterinary Medicine, \\ Patuakhali Science and Technology University, Babugonj Campus, Barisal-8210, Bangladesh.
}

\begin{abstract}
A study was aimed to determine the prevalence of sub-clinical mastitis and also determine the other risk factors that intensify this condition. Prescribed questionnaire was used to take baseline information of the animals and farms and California mastitis test kit was used to determine the SCM in lactating cow at farm level. It appears from this study that an overall prevalence of SCM was $51.56 \%$ in milking cows at Banaripara Upazilla, Barisal. Crossbred cows were significantly affected with SCM than local breed lactating cows. The farm type affect significantly $(p<0.05)$ on the occurrence of this diseases. The prevalence of sub-clinical mastitis in cow was significantly $(\mathrm{p}<0.05)$ higher in $3^{\text {rd }}(80 \%)$ parity compared to $1^{\text {st }}$ $(38.09 \%)$ and $2^{\text {rd }}(45.83 \%)$ parity as well as non pregnant cows $(55.55 \%)$ are more prone to infection than pregnant cow $(46.43 \%)$. The farm floor condition and aged cows don't have any effect on SCM. Prevalence of sub-clinical mastitis was significantly $(\mathrm{p}<0.05)$ higher in high yielding $(87.5 \%)$ cows than medium $(70 \%)$ to low $(33.33 \%)$ yielding cows. A well documented continued research and educational effort is required to increase producer awareness of cost due to mastitis to the dairy enterprise. From this study it was concluded that cow breed, farm type, parity of cows, physiological status of animal and milk yield per cow were found to be important risk factors associated with the occurrence of sub clinical mastitis in dairy cows. The occurrence of this disease remains a substantial problem for dairy producers.
\end{abstract}

Keywords: Prevalence, sub-clinical Mastitis, California Mastitis Test, Barisal.

\section{INTRODUCTION}

Bovine mastitis is a single most common disease syndrome of adult dairy cows recognized mainly as clinical and sub-clinical types worldwide, which has great economic impact on dairy industry with complex multifactorial etiology (Nooruddin et al., 1997). About $75-80 \%$ mastitis is subclinical, characterized by a significantly increased leukocyte count in milk (Bradley, 2002). In subclinical mastitis (SCM), there are no obvious clinical signs. Instead there is an increase in somatic cell counts of the milk (Radostits et al., 2000).

SCM persists in the udder without causing any gross abnormality both in the gland and milk and only could be known only after laboratory examination. This condition is very much important due to the fact that it is about 15 to 40 times more prevalent than the clinical form, persists for long duration, difficult to detect, adversely affects milk quality and constitutes and act as a reservoir of microorganisms that can affect other animals within the herd due to its contagious nature (Schultz et al., 1978). In Bangladesh contest this condition is more serious and causes much greater loss to the dairy industry every year. Some risk factors like pendulous udder with long teats, larger size of teat orifice in high yielding cows, traumatic injuries etc. may play an important role as inciting of mastitis. Predisposing factors such as poor management and hygiene and faulty milking machines are known to hasten the entry of infectious agents and the course of the disease (Majic et al., 1993). In terms of economic loss mastitis is undoubtedly the most important disease with which the dairy industry has to contend. Once a cow suffers from mastitis it will never return to its normal milk production. Kader et al. (2003) reported that the annual economic loss due to reduced milk production alone caused by SCM in Bangladesh is Tk. 122.6 million (US \$ 2.11 million). Besides causing huge losses to milk production, the sub-clinically affected animals remain a continuous source of infection to other herd mates. The prevalence of SCM in dairy cows may develop clinical mastitis at any time under certain stress factor(s). Early diagnosis of sub-clinical mastitis is essential because changes in the udder tissue take place much earlier than they become apparent and also could reduce the production cost as well as help to take necessary action to prevent clinical mastitis. Several diagnostic techniques have been used elsewhere like california mastitis test (CMT),

*Corresponding e-mail address: dibyenducvasu@gmail.com 
white slide test (WST) and surf field mastitis test (SFMT) that are considered as simple, easily applicable, rapid indirect screening tests for determining SCM. Among them validity of CMT in diagnosis of SCM was established very well in various milking stages. Prodhan et al. (1996) reported that the prevalence of sub-clinical mastitis in milch cows was $16.25 \%$ with WST and $15.52 \%$ with CMT at Baghabari, Shirajgonj. Information on SCM in local and cross breed cows is however scanty. Especially, no study has been taken to find out on SCM in Banaripara upazilla of Barisal District. However, presently attempt was made to quantify the occurrence of SCM and associated risk factors. Therefore, the objectives of the present study were: to determine the prevalence of bovine SCM in local and cross breed cow and to determine associated risk factors in the study area.

\section{MATERIALS AND METHODS}

\section{Study area and period}

The study was carried out at Banaripara, Barisal. The study was conducted during the period from $23^{\text {rd }}$ March to $14^{\text {th }}$ May, 2014.

\section{Data collection}

Before taking samples the data was recorded through prescribed questionnaire. Dairy cows from small, medium and large farm are source of population. Cross and local breeds are available among dairy cows.

\section{California Mastitis Test}

Milk samples were collected aseptically from individual quarter of udder. The CMT was performed using Leucocytest ${ }^{\circledR}$ (France) according to company direction. Briefly, a plastic paddle with four receptacles was used for this purpose. After cleaning the teats, $2 \mathrm{ml}$ of foremilk was stripped from 4 teats of each cow separately into the respective cup of the paddle. Equal amount $(2 \mathrm{ml})$ of reagent was added to milk in each cup of the plastic paddle. Then the reagent and milk were mixed in the cups of the plastic paddle by a swirling motion. The result was evaluated immediately by visual examination. No coagulation or gel formation of milk was regarded as negative for subclinical mastitis and coagulation or gel formation of milk was regarded as positive for subclinical mastitis.

\section{Grading of sub clinical mastitis milk}

i) Negative (-ve): The mixture remained fluid without thickening or gel formation.

ii) Trace $( \pm)$ : A slight slime formation was observed. This reaction was most noticeable when the paddle was rocked from side to side.

iii) Moderate (+): Distinct slime formation occurred immediately after mixing the solution and milk. This slime sometime dissipated over time. When the paddle was swirled, fluid neither formed a peripheral mass nor did the surface of the solution become convex or "domed up".

iv) Distinct (++): Distinct slime formation occurred immediately after mixing the solution with milk. When the paddle was swirled, fluid formed a peripheral mass and the bottom of the cup used to be exposed.

v) Strong $(+++)$ : Distinct slime formation occurred immediately after mixing the solution with milk. This slime dissipated over time. When the paddle was swirled, the surface of the solutions became convex or "domed up".

\section{Statistical analysis}

The data obtained from the questionnaire and laboratory tests are analyzed by MS/Excel and SPSS statistical system. The data were organized to generate other variables including age, breed, parity, lactating time, herd size, milk yield. The prevalence of sub-clinical mastitis was calculated as the percentage of SCM affected cows out of the total lactating cows. 


\section{RESULTS AND DISCUSSION}

\section{Prevalence of sub-clinical mastitis compared with clinical mastitis}

A total of 64 dairy cows handled at Banaripara Upazilla, Barisal. The study was conducted during the period from March to May; 2014. Among them 33(51.56\%) cows were positive to CMT. In this study, the overall prevalence of subclinical mastitis was $51.56 \%$ in lactating cows (Table-1). This result was supported by other findings (Singh and Baxi, 1988) who reported that $54.0 \%$ prevalence of subclinical mastitis in cows in India.

Table 1. Prevalence of sub-clinical mastitis in cows at Banaripara Upazila, Barisal.

\begin{tabular}{ccc}
\hline $\begin{array}{c}\text { Total No. of cow } \\
\text { Examined }\end{array}$ & $\begin{array}{c}\text { No. of cow affected with sub-clinical } \\
\text { mastitis }\end{array}$ & $\begin{array}{c}\text { Prevalence of sub-clinical mastitis } \\
(\%)\end{array}$ \\
\hline 64 & 33 & $51.56 \%$ \\
\hline
\end{tabular}

Islam et al. (2011) who reported $29 \%$ overall prevalence of subclinical mastitis in lactating cows of Tangail, Bangladesh. Prodhan et al. (1996) reported a lower prevalence (15.8\%) of subclinical mastitis in cows of Baghabari milkshed area, Shirajgonj, Bangladesh. These differences of prevalence rates of subclinical mastitis might be due to difference of breeds of animals, management practices and the tests used for screening of the milk samples.

\section{Prevalence of sub-clinical mastitis in different types of breed}

In this study, the prevalence of subclinical mastitis was significantly higher $(\mathrm{p}<0.05)$ in crossbreds cows (64.28\%) compared to local cows (27.27\%) (Table 2). This result is similar with the view of Rahman et al. (1997) and Nooruddin et al. (1997) who recorded higher frequency of sub-clinical mastitis in cross breeds. Cross breed cows produce more milk than the local zebus. Bigger size, long, and pendulous udder in cross breed cow might have picked up more infection resulting higher rate of infection.

Table 2. Prevalence of Sub-clinical mastitis in different types of breed.

\begin{tabular}{ccccc}
\hline Types of breed & No. of cows & No. of affected cows & Prevalence (\%) & P-value \\
\hline Cross & 42 & 27 & 64.28 & \multirow{2}{*}{0.00489} \\
Local & 22 & 6 & 27.27 & \\
\hline
\end{tabular}

\section{Prevalence of sub-clinical mastitis in relation to farm type}

It was observed that the prevalence of subclinical mastitis was comparatively higher in large (75\%) farm compared to medium (33.33\%) and small (46.34\%) sized farm but this is no any significant difference $(\mathrm{P}>0.05)$. However, SCM was significantly higher $(\mathrm{p}<0.05)$ in large sized farm than small sized farm. This observation can support the report of Rahman et al. (2009). Certain herd factors can increase the risk of SCM due to specific mastitis pathogens. In case of large herd size the pathogen are spread rapidly than small herd size. This statement can also support the report of Nooruddin et al. (1997) they reported that percentage of SCM is higher in large and medium farm.

Table 3. Prevalence of Subclinical mastitis in relation to farm type

\begin{tabular}{lccccc}
\hline Farm type & $\begin{array}{c}\text { Total No. of } \\
\text { Farm }\end{array}$ & $\begin{array}{c}\text { Total No. of } \\
\text { cows }\end{array}$ & $\begin{array}{c}\text { Total No. of cows } \\
\text { examined }\end{array}$ & $\begin{array}{c}\text { Total No. of } \\
\text { Affected Cows }\end{array}$ & Prevalence (\%) \\
\hline Large $(>16)$ & 1 & 63 & 16 & 12 & $75 \%$ \\
Medium (6-15) & 4 & 24 & 5 & 2 & $40 \%$ \\
Small (1-5) & 35 & 104 & 43 & 19 & $44.18 \%$ \\
Overall difference & & & & $\mathrm{P}=0.094$ \\
Comparative difference & & & $\mathrm{P}=0.1473$ \\
Large versus Medium & & & $\mathrm{P}=0.0439$ \\
Large versus Small & & & $\mathrm{P}=0.8583$ \\
Medium versus Small & & & & \\
\hline
\end{tabular}


Prevalence of mastitis in different parity of dairy animals

Parity plays an important role in causing sub-clinical mastitis. The prevalence of sub-clinical mastitis in cows at different parity was presented on Table-4. There was no any significant difference among this parity group but when comparison was done between $1^{\text {st }}$ and $3^{\text {rd }}$ lactation the SCM was significantly higher $(p<0-05)$ in $3^{\text {rd }}$ lactation compared to $1^{\text {st }}$ lactation. This result is in agreement with the observation made by Sing et al. (1982) who reported highest prevalence rate of sub-clinical mastitis in $2^{\text {nd }}$ parity than $1^{\text {st }}$ one. The finding of present study also support with the findings of Rasool et al. (1985) who observed an increased prevalence of sub-clinical mastitis in old animals.

Table 4. Prevalence of sub-clinical mastitis in accordance to different parity of dairy cow.

\begin{tabular}{cccc}
\hline Parity status & Total no. of cows examined & Total no. of affected cows & Prevalence $(\%)$ \\
\hline $1^{\text {st }}$ & 21 & 8 & $38.09 \%$ \\
$2^{\text {nd }}$ & 24 & 11 & $45.83 \%$ \\
$3^{\text {rd }}$ & 10 & 8 & $80 \%$ \\
$4^{\text {th }}$ & 9 & 6 & $66.67 \%$ \\
Overall difference & & & $\mathrm{P}=0.095$ \\
Comparative difference & & $\mathrm{P}=\mathrm{NS}$ \\
$1^{\text {st }}$ parity versus $2^{\text {nd }}$ parity & & $\mathrm{P}=0.0291$ \\
$1^{\text {st }}$ parity versus $3^{\text {rd }}$ parity & & $\mathrm{P}=\mathrm{NS}$ \\
$1^{\text {st }}$ parity versus $4^{\text {th }}$ parity & & $\mathrm{P}=\mathrm{NS}$ \\
$2^{\text {nd }}$ parity versus $3^{\text {rd }}$ parity & & $\mathrm{P}=\mathrm{NS}$ \\
$3^{\text {rd }}$ parity versus $4^{\text {th }}$ parity & & \\
\hline
\end{tabular}

\section{Prevalence of sub-clinical mastitis on reproductive state}

The prevalence of sub-clinical mastitis on reproductive state was presented in the table 6 . The prevalence of subclinical mastitis was comparatively higher in non pregnant $57.14 \%$ compared to pregnant cows $46.43 \%$ but this is no any significant difference $(\mathrm{P}>0.05)$.

Table 5. Prevalence of sub-clinical mastitis according to different reproductive status of animals.

\begin{tabular}{ccccc}
\hline status & Total No. of cows & Total No. of affected cows & Percentage (\%) & P-value \\
\hline Pregnant & 28 & 13 & $46.43 \%$ & 0.47 \\
Non pregnant & 35 & 20 & $55.55 \%$ & \multirow{2}{*}{0.47} \\
\hline
\end{tabular}

In pregnant animal the amount of milk production is reduced due to lower amount of prolactin release and lower nutritional level because fetus takes a great part on nutrition. Low milk production is less prone to subclinical mastitis (Nulin et al., 1989).

\section{Prevalence of sub-clinical mastitis of cow depending on floor component}

SCM was comparatively higher in brick block floor than soiled floor but there was no significant difference $(\mathrm{P}>0.05)$. This can be explained by the fact that farms with soil floor would dry more quickly than the brick floor (Hogan et al. 1990). As a result soiled floor animal were less affected than brick block floor. But wet brick floors are most harmful for dairy animal to cause sub-clinical mastitis. It appeared that the floor was a potential source for sub-clinical mastitis organisms to enter the udder through the teat orifice.

Table 6. Prevalence of Sub-clinical mastitis of cow depending on floor component

\begin{tabular}{ccccc}
\hline Floor condition & No.of cows examined & No. of affected Cows & Prevalence (\%) & P-value \\
\hline Brick block floor & 53 & 30 & $56.60 \%$ & \multirow{2}{*}{0.0765} \\
Soiled floor & 11 & 3 & $27.27 \%$ & \\
\hline
\end{tabular}




\section{Prevalence of Sub-clinical mastitis in relation to the age group of cows}

It was observed that there is no any significant difference of SCM occurrence in different age group (Table-7). However, the prevalence is gradually increased in according with age. But these results were not agreed with other result. In this study very limited number of animals was studied.

Table 7. Prevalence of Sub-clinical mastitis in relation to the age group of cows

\begin{tabular}{ccccc}
\hline Age of cows (Yr) & No. of cows examined & No. of affected cow & Prevalence (\%) & P value \\
\hline $1-3$ & 17 & 10 & $58.82 \%$ & \\
$4-6$ & 42 & 24 & $57.14 \%$ & $\mathrm{P}=0.9877$ \\
$>6$ & 5 & 3 & $60.00 \%$ & \\
\hline
\end{tabular}

Prevalence of Sub-clinical mastitis in relation to the milk yield per cows

The association between the milk yield per cow per day and SCM was significant $(\mathrm{p}<0.05)$. The prevalence of SCM was comparatively higher in medium to high yielding cows $(87.5 \%)$ than low yielding cow (Table 8$)$. This finding was in agreement with the reports of Kader et al. (2003).

Table 8. Prevalence of SCM in relation to milk yield/day

\begin{tabular}{lccc}
\hline Milk yield/day & No. of Cows examined & No. of affected cows & Prevalence (\%) \\
\hline Low (1-5L) & 36 & 12 & $33.33 \%$ \\
Medium (6-10L) & 20 & 14 & $70 \%$ \\
High (>10L) & 8 & 7 & $87.5 \%$ \\
Overall difference & & & $\mathrm{P}=0.030$ \\
Comparative difference & & \\
High versus Medium & & $\mathrm{P}=0.334$ \\
High versus Low & & $\mathrm{P}=0.0031$ \\
Medium versus Low & & $\mathrm{P}=0.0084$ \\
\hline
\end{tabular}

\section{CONCLUSION}

The prevalence of subclinical mastitis in crossbred cattle is more than that of local cattle. The prevalence of subclinical mastitis is also higher in large farm type dairy farm. Other risk factors including parity, animal physical status and milk yield per day are closely co-related. A well documented continued research and educational effort is required to increase producer awareness of cost due to mastitis to the dairy enterprise.

\section{ACKNOWLEDGEMENT}

This work was supported by a grant from Patuakhali Science and Technology University Research Center, Dumki, Patuakhali, Bangladesh.

\section{REFERENCES}

1. Bradley A (2002). Bovine mastitis: an evolving disease. Veterinary Journal 164: 116-128.

2. Hogan JS, Smith KL, Todhunter DA and Schoenberger PS (1990). Bacterial counts associated with recycled chopped newspaper bedding. Journal of Dairy Science 73: 1756-1767.

3. Islam MA, Islam MZ, Islam MA, Rahman MS and Islam MT (2011). Prevalence of subclinical mastitis in dairy cows in selected areas of Bangladesh. Bangladesh Journal of Veterinary Medicine 9: 73-78.

4. Kader MA, Samad MA and Saha S (2003). Influence of host level factors on prevalence and economics of subclinical mastitis in dairy cows in Bangladesh. Indian Journal of Dairy Science 56: 235-240.

5. Majic B, Jovanovic BV, Ljubic Z and Kukovics S (1993). Typical problems encountered in Croatia in the operation of goats milking machines. Proceedings of the $5^{\text {th }}$ International symposium on machine milking of small ruminants. Budapest, Hungary. pp. 377-379.

6. Nooruddin M, Rahman MS and Rahman MM (1997). Prevalence distribution of mastitis in crossbred and exotic dairy cows. Bangladesh Veterinary Journal 14: 14-44.

D. Biswas and T. Sarker 
7. Nulin, AM, Paape MJ and Nickerson SC (1989). Comparison of phagocytosis and chemiluminescence by blood and mammary gland neutrophils from multiparous and nulliparous cows. American Journal of Veterinary Research 9: 172-177.

8. Prodhan MAM, Kamal AHM and Mahbub-E-Elahi ATM (1996).Prevalence of subclinical mastitis in cows of Baghabari milkshed area. Bangladesh Veterinary Journal 30: 59-61.

9. Radostits OM, Gay CC, Blood DC and Hinchcliff KW (2000). Mastitis. In: Veterinary Medicine, A Textbook of the Diseases of Cattle, Sheep, Pigs, Goats and Horses. $9^{\text {th }}$ Edn, W B Saunders Co. Philadelphia, USA pp. 603-612.

10. Rahman MA, Bhuiyan MMU, Kamal MM and Shamsuddin M (2009). Prevalence and risk factors of mastitis in dairy cows. The Bangladesh Veterinarian 26: 54-60

11. Rasool G, Jabbar MA, Kazmi SE and Ahmed A (1985). Incidence of sub-clinical mastitis in Nilli-Ravi buffaloes and Sahiwal cows. Pakistan Veterinary Journal 5: 76-78.

12. Schultz LH, Broom RW, Jasper DE, Berger RWM, Natwke RP, Phil-pot WN, Smith JW and Thompson PD (1978). Current Concepts of Bovine Mastitis. 2nd Edn., National Mastitis Council, Washington, DC, USA, pp: 69.

13. Sing KB and Baxi KK (1982). Studies on the etiology in vitro sensitivity and treatment of subclinical mastitis. Indian Veterinary Journal 61:176-177. 